\title{
The effects of various dietary vegetable oil sources on villi morphology and liver aldehydes in young layers
}

\author{
Sh. Golzar Adabi, ${ }^{1,2 \#}$, A. Hajibabaei ${ }^{1}$, N.H. Casey $^{1}$ \& A.G. Bayraktaroglu ${ }^{3}$ \\ ${ }^{1}$ Department of Animal and Wildlife Sciences, University of Pretoria, Pretoria 0002, South Africa \\ ${ }^{2}$ Faculty of Agriculture, Department of Animal Science, Ankara University, Turkey \\ ${ }^{3}$ Department of Histology and Embryology, Faculty of Veterinary Medicine, Ankara University, Turkey
}

(Received 11 April 2014; Accepted 15 June 2015; First published online 11 March 2016)

Copyright resides with the authors in terms of the Creative Commons Attribution 2.5 South African Licence.
See: http://creativecommons.org/licenses/by/2.5/za
Condition of use: The user may copy, distribute, transmit and adapt the work, but must recognise the authors and the South African
Journal of Animal Science.

\begin{abstract}
Twenty-six-week-old laying hens (90 Lohmann Classic Brown) received dietary treatments containing canola and linseed oil at $2 \%$ inclusion levels and a control diet for 21 days. The $2 \%$ dietary linseed oil, which had higher total polyunsaturated fatty acids (IPUFA) and linolenic fatty acid contents, resulted in higher liver malondialdehyde and wider villi than the control group. The $2 \%$ canola and linseed oil treatments recorded smaller reproductive organs relative to live weight than the control group. It was concluded that young layers might have an anatomical response to high levels of dietary PUFA, which might improve nutrient absorption and cause a biochemical response, resulting in potentially negative cytotoxic aldehydic lipid peroxidation products.
\end{abstract}

Keywords: Intestine morphology, malondialdehyde, n-3, poultry, PUFA

\#Corresponding author: adabishahram@gmail.com

\section{Introduction}

Fats and oils are added to poultry diets as energy sources and as a means of decreasing the dustiness of the feed (Celebi \& Macit, 2009). Owing to the beneficial effects of $n-3$ polyunsaturated fatty acids (PUFA) on human health and the ability of laying hens to deposit dietary lipids into the egg yolk, many studies have focused on the enrichment of egg yolk with n-3 PUFA (Celebi \& Macit, 2009; Nain et al., 2012). Animals cannot convert n-6 PUFA ( $\alpha$-linolenic acid) to n-3 PUFA (eicosapentaenoic acid; C20:5n-3 and docosahexaenoic acid; C22:6n-3) or vice versa. These two classes of fatty acids (FA) compete with each other in metabolic processes (Wang et al., 2012). Exogenous sources of these FAs are essential in providing the body's daily requirement of n-3 PUFA (Molendi-Coste et al., 2011). Various functional and biological roles of n-3 PUFAs have been reviewed by Ruxton et al. (2005) and Yashodhara et al. (2009).

The presence of more than two isolated double bonds makes these FAs highly susceptible to oxidation. Lipid autoxidation causes the formation of FA hydroperoxides, which then decompose to a wide variety of isomeric secondary oxidation products, such as monohydroperoxides, cyclic epidioxides and dihydroperoxide (Kamal-Eldin et al., 2003; Fraeye et al., 2012). Oxidized and degenerated products of FA, when absorbed by living organisms, might have harmful and adverse biological effects (Botsoglou et al., 2012).

The small intestine's role in nutrient digestion and absorption has been proved, especially the intestinal villi and absorptive epithelial cells. Various researchers have reported the effects of types of diet on the anatomical changes of the gut and alterations of villus shape (Incharoen et al., 2010). Gut health maintenance consumes $20 \%$ of body energy expenditure. Gut health and gut integrity protection are mainly at the centre of nutritionists' attention because any dietary factor that affects the gut health would alter the bird's nutrient uptake, requirements and growth efficiency (Choct, 2009).

Moreover, it seems that recent studies have focused on enriching the eggs with various levels and sources of $n-3$, with less emphasis on their effects on the intestinal morphology and on oxidation level of the liver. Hence, the current study aimed at investigating in young layers the effects of short-term dietary supplementation of cold processed vegetable oils that are high in PUFA on their reproductive system weight, intestine morphology, liver malondialdehyde, serum total cholesterol and triglyceride concentrations. 


\section{Materials and Methods}

Twenty-six-week-old laying hens (90 Lohmann Classic Brown) $(n=90)$ obtained from a commercial farm, were subjected to three dietary treatments with five replicates and six birds per replicate $(3 \times 5 \times 6$ completely randomized design) for 28 days. The birds were vaccinated against the standard avian diseases and kept in individual cages at Hatfield Research Farm, University of Pretoria, South Africa in a naturally ventilated layer house with bird proofing under uniform management and environmental conditions. The first week of the study served as the adaptation period. The treatment period was 21 days from 5 to 26 April 2012, that is, the autumn season.

The diets were formulated to meet the minimum nutrient requirements of Lohmann Classic Brown layer hens based on the National Research Council (NRC, 1994). All experimental groups received a diet containing $151.9 \mathrm{~g} \mathrm{CP}, 10.84 \mathrm{MJ} \mathrm{ME}, 39.2 \mathrm{~g}$ calcium, $4.9 \mathrm{~g}$ available phosphorus, $6.9 \mathrm{~g}$ lysine and $6.7 \mathrm{~g}$ methionine + cysteine $/ \mathrm{kg}$ dry matter (DM) during the study. The experimental diets were in mash form and the diets and drinking water were provided ad libitum.

Treatments consisted of T1: control group; T2: $2 \%$ dietary canola oil; T3: $2 \%$ dietary linseed oil. The FA profiles of the dietary oils and diets were determined. The sample preparation for gas chromatography was according to the method presented by Alonso et al. (2004) and Genet (2004). The lipid profile was determined by gas chromatography (Shimadzu GC-2010 Plus, High-end Gas Chromatograph). Each FA was identified in the form of a methyl ester by comparing the retention times with the Supelco 37 Component FAME Mix standard acquired at Sigma Interlab A.S. (Interlab South Africa). The FA results are presented in Table 1.

There was no mortality during the experiment. Eggs from each replicate were collected twice daily, and the number of eggs produced (eggs/hen/day) was recorded throughout the experimental period. Egg (unwashed and unclassified samples) and yolk weight were determined individually in eggs collected over two days at the end of the experiment. To determine egg yolk weight, the egg yolk was separated from the albumen. The yolk was rolled on a damp paper towel to dry the remaining albumen residue. The chalaziferous were carefully removed with forceps before the yolk was weighed (Golzar Adabi et al., 2013).

At day 21 of the study, two birds were selected randomly from each replicate (total of 10 birds per treatment) and killed by exsanguination. Blood samples were collected in tubes containing heparin, and centrifuged at $3500 \mathrm{rpm}$ for $10 \mathrm{~min}$ to obtain the serum for cholesterol and triglyceride analysis (Pars Azmoon Commercial Kits, Tehran, Iran). Live weight, carcass weight, liver weight, abdominal fat weight, reproduction system weight and gut length (from the duodenum to ileocecal junction) were recorded. The whole reproductive system (oviduct, ovary, large and small follicles) was carefully separated and weighed. The oviduct was cautiously separated to avoid damage to follicles. The oviduct was also examined to remove any eggs before weighing. Liver malondialdehyde analysis $(\mathrm{mg} / \mathrm{kg})$ was performed using the method described by Pfalzgraf et al. (1995).

The morphology of intestinal villi was measured on $5 \mathrm{~cm}$ segments taken $8 \mathrm{~cm}$ proximal to Meckel's diverticulum and preserved with $10 \%$ formalin solution. The samples were embedded in paraffin and sliced into $6 \mu \mathrm{m}$ thick sections, placed on glass slides and stained with Mallory's modified triple staining technique. The slides were examined with a light microscope equipped with a camera (Leica CME, Leica Microsystems Inc., Buffalo, New York, USA). Villus height was measured from the top of the villus to the villus-crypt junction. Crypt depth was defined from the base upwards to the region of transition between the crypt and villus. The results were evaluated with Image $\mathrm{J}$ analysis software (http://imagej.nih.gov/ij). Villus surface area was calculated using this formula, namely $(2 \pi) \times$ (villus width $/ 2) \times\left(\right.$ villus length) $/ 10^{6}$ (Culling et al., 1985; Solis de los Santos et al., 2005; Nain et al., 2012).

The data were analysed with the general linear model procedure of SAS software (SAS, 2001, SAS Institute, Cary, NC, USA). All percentage data were subjected to arcsin square root transformation (Steel \& Torrie, 1960). When necessary, mean separation was accomplished by applying the Tukey's HSD test. A probability $P$-value of less than 0.05 was considered significant.

The Animal Ethics Committee, University of Pretoria approved the project, reference EC27-12.

\section{Results}

The diets differed in their FA profiles. The control diet (T1) had $32.3 \%$ oleic acid, and non-detectable levels of linoleic and linoleic acid. The canola oil diet (T2) contained $43.1 \%$ oleic, $34.9 \%$ linoleic and $4.9 \%$ linoleic acid. The linseed oil diet contained $26.2 \%$ oleic, $34.7 \%$ linoleic and $22.2 \%$ linolenic acid. Owing to the high level of stearic acid and no linoleic or linolenic acid, the control diet had a higher $\Sigma$ PUFA level (43.2\%) compared with the canola oil diet (39.7\%) while the linseed oil diet had the highest $\Sigma$ PUFA level (56.9\%). The canola dietary treatment contained the highest $\Sigma$ MUFA level (43.1\%) (Table 1).

The dietary treatments had no significant effect $(P>0.05)$ on final live weight, live weight changes over the period, carcass weight, liver weight, abdominal fat weight, gut length, gut length to bodyweight, egg 
weight, yolk weight, blood total cholesterol and blood triglyceride among treatment birds. However, the canola and linseed oil dietary treatments recorded a low whole reproduction system weight ratio to bodyweight $(P<0.05$; Table 2$)$.

In this study, dietary treatments had no effect $(P>0.05$; Table 3$)$ on villus length, crypt depth, villus surface area, villus length to crypt depth and tunica muscularis thickness. A significant difference was the width of the villus recorded by the linseed oil dietary treatment $(227.3 \mu \mathrm{m} ; P<0.05$; Table 4) compared with the control and canola oil dietary treatments (165.0 and $176.2 \mu \mathrm{m}$, respectively).

Table 1 Fatty acid profiles of experimental diets and oils presented as percentage of total fatty acid

\begin{tabular}{|c|c|c|c|c|c|c|}
\hline \multirow{2}{*}{ Fatty acid } & & \multicolumn{3}{|c|}{ Treatments } & \multicolumn{2}{|c|}{ Oils } \\
\hline & & Control & $2 \%$ canola oil & $2 \%$ linseed oil & Canola & Linseed \\
\hline Palmitic & $16: 0$ & 19.26 & 13.99 & 12.96 & 12.78 & 6.53 \\
\hline Stearic & $18: 0$ & 4.50 & 3.17 & 3.88 & 5.14 & 3.71 \\
\hline Oleic & $18: 1 n-9$ & 32.32 & 43.12 & 26.22 & 59.27 & 20.29 \\
\hline Linoleic & $18: 2 n-6$ & & 34.85 & 34.72 & 16.68 & 16.06 \\
\hline Linolenic & $18: 3 n-3$ & nd & 4.88 & 22.22 & 6.13 & 53.21 \\
\hline$\Sigma$ SFA & & 23.37 & 17.16 & 16.83 & 17.92 & 10.23 \\
\hline ¿MUFA & & 32.32 & 43.12 & 26.22 & 59.27 & 20.29 \\
\hline$\Sigma$ PUFA & & 43.19 & 39.73 & 56.94 & 22.81 & 69.47 \\
\hline$n-6: n-3$ & & 43.19 & 7.14 & 1.56 & 2.72 & 0.30 \\
\hline
\end{tabular}

$\Sigma$ SFA = total saturated fatty acids; $\Sigma$ MUFA = total monounsaturated fatty acids;

$\Sigma$ PUFA $=$ total polyunsaturated fatty acids

\section{Discussion}

Recently, Ahmad et al. (2012) reviewed the effect of dietary omega-3 fatty acids on performance and egg quality of laying hens. They reported that dietary inclusion of n-3 PUFA in laying hens had no effect on egg production and egg characteristics except for a decrease in whole egg weight and egg yolk weight. They also discussed the mechanism of such reduction in their article. In the current study, dietary canola and linseed oil had no significant effect on laying performance, egg and yolk weight. Grobas et al. (2001) showed that laying hens fed a diet containing $5 \%$ or $10 \%$ linseed oil during 12 weeks trial period produced eggs with the same yolk weights, egg weight and egg mass as control birds. The same results were reported by Beynen (2004) and Sosin et al. (2006) on the yolk weight, but not the egg weight. They revealed that egg weight decreased significantly $(P<0.05)$ by feeding linseed to the hens. In another study, Silke et al. (2008) showed that dietary soybean oil and/or linseed oil had no effect on egg weight in laying hens.

In the current study, the control birds had the highest relative whole reproduction system weight to final live bodyweight $(\mathrm{kg} / \mathrm{kg}$ ) compared with birds fed a diet containing canola and linseed oil.

It has been reported that dietary n-3 (fish oil) caused a significant decrease in blood oestrogen level (Whitehead et al., 1993). On the other hand, previous studies showed that treatment of oestradiol regulates oviduct differentiation and function in young laying hens, and enhances oviduct growth by increasing the size, weight and content of the tissue protein, RNA, and DNA in Japanese quails (Schimke et al., 1975; Boogard \& Fnnengan, 1976). Furthermore, there is a positive relationship between oestrogen and prostaglandin F, because Takahashi et al. (2004) observed an increase in prostaglandin F concentration and the specific binding of $\left[{ }^{3} \mathrm{H}\right] \mathrm{E}_{2}$ of oestrogen receptor in the uterine tissue of laying hens by injecting estradiol17ß. Moreover, Guo et al. (2004) and Eilati et al. (2013) observed the lowest synthesis of prostaglandin E2 in hens receiving fish oil and flaxseed, respectively. In this sense, it seems that reduction in reproduction system weight in the current study is related to hormonal changes in hens that received n-3 oil via the diet.

In the current study, blood total cholesterol and triglyceride concentrations were not affected by dietary oil inclusion. In contrast with these results, Svedova et al. (2008) observed that serum total cholesterol and $\mathrm{HDL}$-cholesterol concentrations decreased and increased, respectively, in laying hens fed a diet containing $3 \%$ linseed oil. However, there are conflicting results, for example, feeding various dietary levels of canola 
seed and linseed had no significant effect on serum cholesterol (Mirghelenj et al., 2004), and Ansari et al. (2006) found no significant change in blood cholesterol levels of laying hens by feeding flaxseed $(0 \%, 5 \%$, $10 \%$ and $15 \%$ of diet). Chapman (1980) and Murata et al. (2003) reported that blood lipid parameters (total cholesterol, HDL-cholesterol, triacylglycerol) were not affected by dietary oil sources (soya, canola, fish and poultry by-product), which this study has also found. Despite the synthesis of egg yolk lipid in the liver and its transportation by blood circulation, no close connection could be identified between plasma cholesterol concentration and egg yolk lipid level (Murata et al., 2003). Beyer \& Jensen (1992) documented that plasma cholesterol shows great variation and concluded that this effect could be because of the synthesis and excretion of cholesterol through the liver and might be associated with the feed intake or the ovulation period of the hen. A possible explanation for the absence of a clear relationship between blood cholesterol and yolk cholesterol might be that the blood cholesterol for the growing oocyte varies rapidly in relation to time.

Table 2 Effects of dietary oil sources on certain parameters of laying hens after 21 days' on the experimental diets

\begin{tabular}{|c|c|c|c|c|c|}
\hline \multirow{2}{*}{ Parameters $^{1}$} & \multicolumn{3}{|c|}{ Treatments } & \multirow{2}{*}{$P$-value } & \multirow{2}{*}{ SEM $^{5}$} \\
\hline & Control & Canola oil & Linseed oil & & \\
\hline Initial live (kg) & 1.818 & 1.772 & 1.772 & 0.763 & 0.027 \\
\hline Final live weight (kg) & 1.761 & 1.877 & 1.798 & 0.354 & 0.032 \\
\hline Live weight changes (kg) & -0.056 & 0.105 & 0.026 & 0.365 & 0.045 \\
\hline Carcass weight (kg) & 1.400 & 1.484 & 1.424 & 0.437 & 0.026 \\
\hline Liver weight (g) & 12.59 & 11.68 & 11.34 & 0.246 & 0.309 \\
\hline Abdominal fat weight (g) & 42.39 & 50.54 & 51.83 & 0.429 & 3.080 \\
\hline $\begin{array}{l}\text { Whole reproduction system weight/final live } \\
\text { bodyweight }(\mathrm{kg} / \mathrm{kg})\end{array}$ & $0.091^{\mathrm{a}}$ & $0.081^{b}$ & $0.084^{b}$ & 0.040 & 0.001 \\
\hline Gut length $(\mathrm{cm})$ & 143.6 & 140.4 & 140.9 & 0.855 & 2.345 \\
\hline Gut length/final live bodyweight (cm/kg) & 81.91 & 75.19 & 78.74 & 0.224 & 1.561 \\
\hline Laying rates $(\%)$ & 93.11 & 92.79 & 93.03 & 0.532 & 1.047 \\
\hline Egg weight $(g)^{2}$ & 55.49 & 54.86 & 54.66 & 0.800 & 0.493 \\
\hline Yolk weight $(g)^{2}$ & 15.14 & 14.35 & 14.64 & 0.460 & 0.249 \\
\hline Liver malondialdehyde $(\mathrm{mg} / \mathrm{kg})^{3}$ & $1.222^{\mathrm{b}}$ & $1.425^{\mathrm{ab}}$ & $1.641^{\mathrm{a}}$ & 0.006 & 0.060 \\
\hline Serum total cholesterol $(\mathrm{mg} / \mathrm{dL})^{4}$ & 210.8 & 209.0 & 210.2 & 0.231 & 0.435 \\
\hline Serum triglyceride $(\mathrm{mg} / \mathrm{dL})^{4}$ & 206.4 & 206.4 & 206.9 & 0.927 & 0.517 \\
\hline \multicolumn{6}{|c|}{$\begin{array}{l}\text { a-b For comparison among birds on different diets, values within a same row that do not share a common superscripts are } \\
\text { significantly different }(P<0.05) \text { according to Tukey's test. } \\
1 \text { bwt: body weight; Carcass weight: empty body weight without skin; Gut length }(\mathrm{cm}) \text { : from the duodenum to ileocecal } \\
\text { junction. } \\
{ }^{2} \text { Means of } 50 \text { random eggs per treatment. } \\
{ }^{3} \text { Means of } 10 \text { measurements per treatment (each sample was determined in duplicate laboratory parallel). } \\
{ }^{4} \text { Means of } 30 \text { measurements per treatment. } \\
{ }^{5} \text { SEM: standard error of mean. }\end{array}$} \\
\hline
\end{tabular}

More recently, Liu et al. (2010) reported that hepatic total cholesterol (mg) and cholesterol concentration ( $\mathrm{mg} / \mathrm{g}$ of wet liver) were not affected in hens receiving graded levels of dietary plant sterols, despite minor reductions in egg yolk cholesterol concentration. On the other hand, Van Elswyk et al. (1994) demonstrated that dietary fish oil supplementation at a 3.0\% inclusion level resulted in decreased serum cholesterol concentration in hens. In another study, laying hens were fed diets that contained different levels of fish oil and flax seed in which dietary treatments had no $(P>0.05)$ effect on the concentrations of serum triglyceride and high density lipoprotein. However, the serum cholesterol level of hens fed diets containing $1.5 \%$ fish $+4.32 \%$ or $8.64 \%$ flaxseed was lower than the control group (Basmacioglu et al., 2003).

Liver malondialdehyde is the result of oxidative degradation of polyunsaturated lipids. As noted, the linseed oil dietary treatment had high SPUFA level (56.9\%) compared with the canola oil ration (39.7\%) and 
linseed oil dietary treatment recorded the highest $(P<0.05)$ liver malondialdehyde $(1.64 \mathrm{mg} / \mathrm{kg})$ compared with the control and canola groups (1.22 and $1.43 \mathrm{mg} / \mathrm{kg}$, respectively). Contradictory results have been obtained from other studies that measured liver malondialdehyde levels after feeding with dietary oil. Liu et al. (2011) found no significant difference in malondialdehyde in duck livers between the control and fish oil and soybean oil treatment diets, whereas geese fed diets with different n-6:n-3 PUFA ratios of $12: 1,9: 1$, $6: 1$ and $3: 1$, had decreasing levels of malondialdehyde as the n-6:n-3 PUFA ratios decreased and were lowest at $3: 1$ and $6: 1$, which occurred across the ages 42,56 , and 70 days of the study $(P<0.05)$ (Wang et al., 2012). A study on rats with experimental non-alcoholic fatty liver disease, fed dietary fish oil derived n-3 PUFA, resulted in increases in liver malondialdehyde concentrations and severe fatty liver (Hussein et al., 2007). This study associates the level of liver malondialdehyde with the high $\Sigma$ PUFA of the linseed oil, which could be deduced to linolenic acid since this FA was markedly higher (Table 1$)$.

Based on the formula $\{(2 \pi) \times$ (villus width $/ 2) \times$ (villus length) $\left./ 10^{6}\right\}$, longer and wider villi increase the villus surface area, which increases the capability for nutrients to be absorbed. Shorter villi and deeper crypts have been reported in some conditions, such as the presence of toxins and the increase of pathogenic bacteria in the intestinal lumen, which are related to fewer absorptive functions and more secretory cells (Solis de los Santos et al., 2005; Choct, 2009; Nain et al., 2012).

lleum morphology findings of this study do not agree with those reported by Nain et al. (2012) on the effect of metabolic efficiency and associated gut characteristics of laying hens on the variability of transfer of dietary n-3 PUFA to the egg in laying hens at 56 weeks old. The source of n-3 PUFA of Nain et al. (2012) was an extruded flax product and fed for 14 days. No significant difference occurred in the average duodenal villus widths for efficient and non-efficient hens. The differences between this study and that of Nain et al. (2012) were the age of the layers and the source of dietary PUFA. It is likely that age is a determining factor and that the young hens are more responsive to dietary influences of this nature. An age effect could have been determined if the trial included a range of ages. This study did not determine nutrient absorption and transit time of digesta as these factors could affect the nutrient availability related to gut morphologic changes (Nain et al., 2012). If it were conclusively shown that a high level of dietary PUFA stimulates significant advantages in the morphological adaptation of the villus and that young animals are more receptive to the influence of the PUFA, the result could have important consequences for the poultry nutrition industry and the efficiency of production.

Table 3 The effects of various dietary oil sources on ileum morphology of laying hens after 21 days of experimental diets

\begin{tabular}{lccccc}
\hline \multirow{2}{*}{ Parameters $^{1}$} & \multicolumn{3}{c}{ Treatments } & \multirow{2}{*}{ P-value } & \multirow{2}{*}{ SEM $^{2}$} \\
\cline { 2 - 4 } & Control & Canola oil & Linseed oil & & \\
\hline Villus length $(\mu \mathrm{m})$ & 1005.9 & 1091.2 & 1088.4 & 0.813 & 58.219 \\
Villus width at mid villus $(\mu \mathrm{m})$ & $165.0^{\mathrm{b}}$ & $176.2^{\mathrm{ab}}$ & $227.3^{\mathrm{a}}$ & 0.029 & 10.744 \\
Crypt depth $(\mu \mathrm{m})$ & 185.7 & 181.0 & 188.7 & 0.951 & 9.416 \\
Villus surface area $\left(\mathrm{mm}^{2}\right)$ & 0.552 & 0.611 & 0.784 & 0.288 & 0.061 \\
Villus length : crypt depth & 5.385 & 6.247 & 5.840 & 0.481 & 0.279 \\
Tunica muscularis thickness $(\mu \mathrm{m})$ & 389.9 & 376.7 & 322.0 & 0.5685 & 26.472 \\
\end{tabular}

\footnotetext{
${ }^{a-b}$ For comparison among birds on different diets, values within a same row that do not share a common superscripts are significantly different $(P<0.05)$ by Tukey's test.

${ }^{1}$ The 10 individual measurements per bird (10 birds from each treatment and totally 30 birds were examined) was measured and the mean value was used for statistical analysis.

${ }^{2}$ SEM: standard error of mean.
}

The linseed oil dietary treatment containing a high level of linolenic and low oleic acids resulted in a potentially negative situation by increasing cytotoxic aldehydic lipid peroxidation products. At the same time, the treatment stimulated the villi of young birds to become wider, thereby presenting a larger surface area for nutrient absorption. In either case, further research is needed to ascertain the risk of PUFA dietary lipids. 


\section{Authors' contributions}

$\mathrm{AH}$ and NHC designed the trial that was done under NHC's supervision. AH submitted the ethics clearance application. SHGA joined the project. The trial was modified into growth phases in consultation with SHGA. AH and SHGA executed the trial and SAGH had the organs analysed at Ankara University, Turkey by AGB. SHGA and AH did the statistical analyses, interpreted the results, wrote the draft paper. NHC and AH checked the results and contributed to preparing the manuscript. NHC funded the project. All authors agreed on the final version.

\section{Conflict of interest declaration}

There were no conflicts of interest.

\section{References}

Ahmad, S., Haq, A.U., Yousaf, M., Sabri, M.A. \& Kamran, Z., 2012. Response of laying hens to omega-3 fatty acids for performance and egg quality. Avian Biol. Res. 5 (1), 1-10.

Alonso, L., Cuesta, E.P. \& Gilliland, S.E., 2004. Gas chromatographic method for analysis of conjugated linoleic acids isomers (c9t11, t10c12, and t9t11) in broth media as application in probiotic studies. J. Chromatogr. Sci. 42, 167-170.

Ansari, R., Azarbayejani, A., Ansari, S., Asgari, S. \& Gheisari, A., 2006. Production of egg enriched with omega-3 fatty acids in laying hens. ARYA J. 1, 242-246.

Basmacioglu, H., Çabuk, M., Unal, K., Ozkan, K., Akkan, S. \& Yalcin, H., 2003. Effects of dietary fish oil and flax seed on cholesterol and fatty acid composition of egg yolk and blood parameters of laying hens. S. Afr. J. Anim. Sci. 33, 266-273.

Beyer, R.S. \& Jensen, L.O., 1992. Cholesterol concentration of egg yolk and blood plasma and performance of laying hens as influenced by dietary a-ketoisocaproic acid. Poult. Sci. 71, 120-127.

Beynen, A.C., 2004. Fatty acid composition of eggs produced by hens fed diets containing groundnut, soybean or linseed. J. Anim. Sci. 52, 3-10.

Boogard, C.L. \& Fnnengan, C.V., 1976. The effects of estradiol and progesterone on the growth and differentiation of the quail oviduct. Can. J. Zool. 54, 324-335

Botsoglou, E., Govaris, A., Fletouris, D. \& Botsoglou, N., 2012. Lipid oxidation of stored eggs enriched with very long chain n-3 fatty acids, as affected by dietary olive leaves (Olea europea L.) or a-tocopheryl acetate supplementation. Food Chem. 134, 1059-1068.

Celebi, S. \& Macit, M., 2009. Effects of feeding tallow and plant fat to laying hens on performance, egg quality and fatty acid composition of egg yolk. J. Appl. Anim. Res. 36, 49-52.

Chapman, D., 1980. Animal lipoproteins: chemistry, structure, and comparative aspects. J. Lipid Res. 21, 789-853.

Choct, M., 2009. Managing gut health through nutrition. Br. Poult. Sci. 50, 9-15.

Culling, C.F.A., Allison, R.T., \& Bar, W.T., 1985. Cellular Pathology Technique. 4th ed. Eds: Culling, C.F.A., Allison, R.T. \& Bar, W.T., Butterworth and Co. Ltd., London. pp. 167-171.

Eilati, E., Hales, K., Zhuge, Y., Ansenberger Fricano, K., Yu, R., Van Breemen, R.B. \& Hales, D.B., 2013. Flaxseed enriched diet-mediated reduction in ovarian cancer severity is correlated to the reduction of prostaglandin $E(2)$ in laying hen ovaries. Prostaglandins Leukot. Essent. Fatty Acids 89 (4), 179-187.

Fraeye, I., Bruneel, C., Lemahieu, C., Buyse, J., Muylaert, K. \& Foubert, I., 2012. Dietary enrichment of eggs with omega-3 fatty acids: A review. Food Res. Int. 48, 961-969.

Genet, T., Labuschagne, M.T. \& Hugo, A., 2004. Capillary gas chromatography analysis of Ethiopian mustard to determine variability of fatty acid composition. J. Sci. Food Agri. 84, 1663-1670.

Golzar Adabi, SH., Ahbab, M., Fani, A.R., Hajibabaei, A., Ceylan, N. \& Cooper, R.G., 2013. Egg yolk fatty acid profile of avian species - influence on human nutrition. J. Anim. Physiol. Anim. Nutr. 97, 27-38.

Guo, Y., Chen, S., Xia, Z. \& Yuan. J., 2004. Effects of different type of polyunsaturated fatty acids on immune function and PGE2 synthesis by peripheral blood leukocytes of laying hens. Anim. Feed Sci. Technol. 116, $249-257$.

Grobas, S., Mendez, J., Lazaros, R., Blas, C.D., Mateos, G.G. \& De, B.C., 2001. Influence of source of fat added to diet on performance and fatty acid composition of egg yolks of two strains of laying hens. Poult. Sci. 80, 1171-1179.

Hussein, O., Grosovski, M., Lasri, E., Svalb, S., Ravid, U. \& Assy, N., 2007. Monounsaturated fat decreases hepatic lipid content in non-alcoholic fatty liver disease in rats. World J. Gastroenterol. 13, 361-368.

Incharoen, T., Yamauchi, K., Erikawa, T. \& Gotoh, H., 2010. Histology of intestinal villi and epithelial cells in chickens fed low-protein or low-fat diets. Italian J. Anim. Sci. 9, 429-434.

Kamal-Eldin, A., Mäkinen, M. \& Lampi, A.M., 2003. The challenging contribution of hydroperoxides to the lipid oxidation mechanism. In: Kamal-Eldin A. Lipid oxidation pathways. AOCS Press, Champaign, Illinois. p. 323.

Liu, W.M., Lai, S.J., Lu, L.Z., Shi, F.X., Zhang, J., Liu, Y., Yu, B., Tao, Z.R., Shen, J.D., Li, G.G., Wang, D.Q., Li, J.J. \& Tian, Y., 2011. Effect of dietary fatty acids on serum parameters, fatty acid compositions, and liver histology in Shaoxing laying ducks. J Zhejiang Univ-Sci B. 12 (9), 736-743.

Liu, X., Zhao, H.L., Thiessen, S., House, J.D. \& Jones, P.J., 2010. Effect of plant sterol-enriched diets on plasma and egg yolk cholesterol concentrations and cholesterol metabolism in laying hens. Poult. Sci. 89, 270-275.

Mirghelenj, A., Rahimi, S. \& Kamali, A., 2004. Effects of omega-3 fatty acid sources in laying hen diets on blood plasma cholesterol. 22nd World Poultry Congress, Istanbul, Turkey 2004.

Molendi-Coste, O., Legry, V. \& Leclercq, I.A., 2011. Why and how to meet n-3 PUFA dietary recommendations? Gastroenterol. Res. Pract. 2011 (364040), 1-11. 
Murata, L.S., Ariki, J., Machado, C.R., da Silva, P.G. \& Rezende, M.J.M., 2003. Effect of oils sources on blood lipid parameters of commercial laying hens. Braz. J. Poult. Sci. 5 (3), 203-206.

Nain, S., Renema, R.A., Zuidhof, M.J. \& Korver, D.R., 2012. Effect of metabolic efficiency and intestinal morphology on variability in n-3 polyunsaturated fatty acid enrichment of eggs. Poult. Sci. 91, 888-898.

NRC, 1994. Nutrient requirements of domestic animals. Nutrient Requirements of Poultry, 9th ed. National Academic Press, Washington, D.C., USA.

Pfalzgraf, A., Frigg, M. \& Steinhart, H., 1995. $\alpha$-Tocopherol contents and lipid oxidation in pork muscle and adipose tissue during storage. J. Agric. Food Chem. 43, 1339-1342.

Ruxton, C.H., Calder, P.C., Reed, S.C. \& Simpson, M.J., 2005. The impact of long-chain n-3 polyunsaturated fatty acids on human health. Nutr. Res. Rev. 18 (Pt 1), 113-129.

SAS, 2001. Statistical Analysis Systems user's guide (9.2th ed.). SAS institute Inc., Statistics. SAS Institute Inc., Cary, North Carolina, USA.

Schimke, R.T., McKnight, G.S., Shapiro, D.J., Sullivan, D. \& Palacios, R., 1975. Hormonal regulation of ovalbumin synthesis in the chick oviduct. Recent Prog. Horm. Res. 31, 175-211.

Silke, H.S., Nutztierethologie, F.G. \& Kleintierzucht, U., 2008. Effect of genetic types with two types of dietary fats on performance and egg yolk fatty acids in laying hens. Eur. Poult. Sci. 72, 177-184.

Solis de los Santos, F., Tellez, G., Farnell, M.B., Balog, J.M., Anthony, N.B., Pavlidis, H.O. \& Donoghue, A.M., 2005. Hypobaric hypoxia in ascites resistant and susceptible broiler genetic lines influences gut morphology. Poult. Sci. 84, 1495-1498.

Sosin, E., Borowiec, F., Strzetelski, J. \& Smulikowska, S., 2006. The effect of feeding regular or low a-linolenic acid linseed on the fatty acid composition of egg yolks. J. Anim. Feed Sci. 15, 641-650.

Steel, R.G.D. \& Torrie, J.H., 1960: Principles and Procedures of Statistics. McGraw-Hill, New York, USA.

Svedova, M., Vasko, L., Trebunova, A., Kasteł, R., Tuckova, M. \& Certik, M., 2008. Influence of linseed and fish oil on metabolic and immunological indicators of laying hens. Acta Vet. Brno. 77, 39-44.

Takahashi, T., Ogawa, H., Inaba, R. \& Kawashima. M., 2004. Changes in prostaglandin F concentration in the uterus (shell gland) of the hen oviduct in relation to oviposition and estrogen. Poult. Sci. 83, 1745-1749.

Van Elswyk, M.E., Hargis, B.M., Williams, J.D. \& Hargis, P.S., 1994. Dietary menhaden oil contributes to hepatic lipids in laying hens. Poult. Sci. 73, 653-662.

Wang, M.Z., Ding, L.Y., Wang, J.F., Yu, L.H. \& Wang, H.R., 2012. Dietary effects of n-6:n-3 polyunsaturated fatty acid ratios on the antioxidant status of the liver in goslings. J. Anim. Feed Sci. 21, 372-382.

Whitehead, C., Bowman, A.S. \& Griffin, H.D., 1993. Regulation of plasma estrogen by dietary fats in the hen: Relationships with egg weight. Br. Poult. Sci. 34, 999-1010.

Yashodhara, B.M., Umakanth, S., Pappachan, J.M., Bhat, S.K., Kamath, R. \& Choot, B.H., 2009. Omega-3 fatty acids: A comprehensive review of their role in health and disease. Postgrad. Med. J. 85, 84-90. 